\title{
Narrativas fundadoras do feminismo: poderes e conflitos (1970-1978)
}

RESUMO

A forma como foram definidas as datas do ressurgimento do feminismo de 'Segunda Onda', na década de 1970, no Brasil, reflete interpretações oriundas de diferentes lugares. A narrativa de 'origem' desse feminismo foi resultado de disputas de poder entre diversos grupos feministas e entre estes e os diversos personagens envolvidos na luta contra a ditadura militar, instalada no país entre 1964 e 1985. As dicotomias entre 'lutas gerais e lutas específicas', de um lado, e entre 'verdadeiramente feministas e nãofeministas', de outro, presentes nessas disputas, falam de poderes e de conflitos.

Palavras-chave: Feminismo; Relações de poder; Ditadura militar; Narrativas.

\begin{abstract}
The way the 'Second Wave' feminism reemergence was defined in the seventies, in Brazil, reflects interpretations that come from different places. The narrative of 'origin' of this feminism was result of contests of power among diverse feminists groups and among these and the diverse characters involved in the fight against the military dictatorship, present in the country between 1964 and 1985. The dichotomy between "general fights versus specific fights", in one side, and "true feminists versus not-feminists" in the other side, present in these contests, talks about powers and conflicts. I intend to discuss, in this article, the invention of these origins and their contests for power.

Keywords: Feminism; Power relations; Military dictatorship; Narratives.
\end{abstract}


Há uma narrativa de 'origem' do ressurgimento do feminismo no Brasil, na década de 1970, que prevalece até os dias atuais. Essa narrativa foi resultado de disputas de poder entre diversos grupos feministas, e entre estes e os diversos personagens envolvidos na luta contra a ditadura militar, instalada no país entre 1964 e 1985. Essa luta envolvia, para uns, as dicotomias entre "lutas gerais e lutas específicas", de um lado, e entre "verdadeiramente feministas e não-feministas", de outro. A forma como foram definidas essas datas reflete interpretações oriundas de diferentes lugares. Fala de poderes e conflitos.

O feminismo que foi retomado no Brasil na década de 1970 tem histórias entrecruzadas e conflitivas. Essas histórias merecem uma análise mais detalhada, visando observar, não necessariamente a verdadeira data brasileira do renascimento do feminismo, mas sim as disputas que se constituíram. É, portanto, a invenção dessas origens e suas disputas pelo poder que pretendo discutir neste texto.

Uma das narrativas fundadoras do feminismo da Segunda Onda ${ }^{1}$ no Brasil informa que, graças à definição, pela ONU — Organização das Nações Unidas, de 1975 como o Ano Internacional da Mulher, e como ano de início da Década da Mulher, aconteceu no Brasil o ressurgimento do movimento feminista 'organizado'. Este teria sido inaugurado com uma reunião, ocorrida em julho de 1975, na ABI — Associação Brasileira de Imprensa, no Rio de Janeiro, e com a constituição do Centro da Mulher Brasileira, também naquela cidade. A partir de então, teria ocorrido o aparecimento de outros espaços de união e movimento feminista em outros lugares do Brasil.

Essa narrativa fundadora informa, também, que o ressurgimento do movimento de mulheres e feminista ${ }^{2}$ em 1975, com o apoio da ONU, teria representado para diversos partidos e grupos políticos, ainda clandestinos, que tentavam se reorganizar em meio à repressão, uma possibilidade e, ao mesmo tempo, uma ameaça. Inicialmente a possibilidade aberta pelo ano Internacional da Mulher foi considerada como um espaço autorizado para fortalecer a luta contra a ditadura, e, portanto, entre os partidos clandestinos, uma possibilidade de reuniões e atuação sob a proteção da ONU, sem que se sentissem ameaçados pela repressão. Entretanto, o fato de 1975 ser o Ano Internacional das Mulheres, tendo resultado de uma luta feminista que recomeçava, foi, também, pensado como uma ameaça ao projeto político de muitos desses grupos, pois poderia significar a 'dispersão' daquilo que consideravam uma luta prioritária.

A história dessas primeiras reuniões — sob a proteção do ano Internacional da Mulher — tem sido narrada e analisada por diversas pesquisadoras. 
O ano de 1975 tem estado na memória de muitas mulheres. As narrativas expõem as múltiplas perspectivas em que viveram aquele momento, e as diferentes leituras que fazem nos dias atuais. ${ }^{3}$ A narrativa daquele momento 'inaugural' começa, para algumas, no início de 1975, quando a ONU realizou uma conferência sobre a Mulher no México. Heloneida Studart ${ }^{4}$ conta, por exemplo, que esteve no México para cobrir esse evento:

eu fui mandada pela revista Manchete para cobrir o Congresso Internacional da Mulher, no México, em 1975 ... de tudo que eu vi, de tudo que eu li que todas as mulheres, quer chinesas, quer européias, quer americanas, todas as mulheres sentiam bem esta dificuldade da relação com o homem. A opressão da relação. Então eu voltei do México com um poncho e com a decisão de fundar uma organização feminista. ${ }^{5}$

É interessante destacar, ainda, desse depoimento, a forma como Heloneida veio a se envolver com o feminismo. Foi nesse evento do México, do qual participou como repórter - portanto um trabalho de sua profissão que ela se deu conta da opressão na relação entre homens e mulheres. Na sua narrativa, esse evento é fundante de sua identificação.

Convém, aqui, destacar a importância do Ano Internacional da Mulher e do apoio da ONU para o Brasil. Vivendo, desde 1964, em plena ditadura militar, durante a qual qualquer reunião, especialmente de grupos constantemente vigiados, constituía um risco muito grande, a Década da Mulher e o Ano da Mulher proporcionaram o lançamento de vários eventos acerca de questões relativas à mulher. Convém destacar, antes de mais nada, que a iniciativa da ONU apenas repercutiu o que estava acontecendo desde os anos 60 e, principalmente, no início dos anos 70, em vários países da Europa e nos Estados Unidos, onde as manifestações feministas enchiam as ruas das cidades reivindicando direitos - entre estes, o de livre disposição do corpo. No Brasil, o evento patrocinado pelo Centro de Informação da ONU, em julho de 1975, no Rio de Janeiro, realizado na ABI, teve o tímido título de "O papel e o comportamento da mulher na realidade brasileira".

Como já dissemos, a lembrança que as entrevistadas têm desse evento são as mais variadas. Muitas delas o vêem como o verdadeiro fundador do feminismo brasileiro da Segunda Onda. Moema Toscano faz sua narrativa:

Tentaram fazer um debate comemorando o Ano Internacional da Mulher, o início da Década da Mulher. E foi um grupo muito interessante que exerceu a 
primeira — vamos dizer - 'liderança', aqui. Chegaram a mim através de uma outra colega da Faculdade de Filosofia que se lembrava de eu já falar nesse assunto, 'mulher'. Falaram no auditório da ABI ... teve uma repercussão enorme no Brasil ... Aconteceu pessoas virem de São Paulo, gente que estava aqui por perto, gente que não era daqui do Rio. Foi todo mundo para a $A B I$... encheu [de gente] e aí sentimos, “é o momento, está na hora!”. Ali nós já fizemos umas reuniões nas outras semanas, fomos nos reunindo. Até que surgiu a idéia de um movimento mais organizado, que foi o Centro da Mulher Brasileira. ${ }^{6}$

Sonia Malheiros Miguel também relata:

Quando eu entrei na universidade, acabei participando do Diretório Acadêmico, fui presidente ... Então me envolvi um pouco com a política de uma maneira geral. Com a questão da mulher. Tinha leituras, algumas, mas eu me lembro de 75, eu fui à palestra que teve na $\mathrm{ABI}$ - Associação Brasileira de Imprensa.?

Maria do Espírito Santo, conhecida como Santinha, também narra:

Quando a gente estava nesse processo de discussão, final do ano de 1975, que foi um ano de registro do feminino no Brasil, nós fizemos o primeiro encontro nacional — olha a ousadia — sobre feminismo. E convidamos companheiras que a gente já conhecia de São Paulo, uma aqui, uma acolá, mas foi basicamente Rio e São Paulo. E nós fizemos na ABI, aqui. E foi uma coisa linda, porque foi um daqueles encontros em que ninguém é importante. Entende? ... Aí veio gente de São Paulo, e criou o Centro da Mulher Brasileira de São Paulo. Então já tínhamos uma perna em São Paulo. ${ }^{8}$

Nas identificações com o feminismo, esse evento tornou-se um marco. Ter participado do evento passou a garantir certa legitimidade da identificação com o feminismo. ${ }^{9}$ As narrativas afirmam que foi nesse evento que surgiu o CMB - Centro da Mulher Brasileira. As instalações ficavam no Rio de Janeiro, numa sala alugada. Entre os objetivos do CMB estavam o "estudo, a reflexão, pesquisa e análise" das questões da mulher, e a "criação de um departamento de ação comunitária para tratar concretamente e em nível local dos problemas da mulher". ${ }^{10} \mathrm{O}$ que elas pretendiam era "combater a alienação da mulher em todas as camadas sociais, para que ela possa exercer o seu papel insubstituível e até agora não assumido no processo de desenvolvimento" (Pinto, 2003, p.58).

Uma das discussões, sempre presentes nos jornais e textos escritos pelo 
campo da esquerda, e também por feministas, era a preocupação com o fato de o país não ter uma 'tradição democrática'. O argumento era de que a longa história de ditaduras e governos de exceção teria impedido que os brasileiros e as brasileiras tivessem uma prática democrática consolidada. Esse era um dos argumentos usados para explicar o porquê do apoio popular aos governos militares - expresso no ufanismo nacionalista do período Médici tempo do chamado 'Milagre Brasileiro'. Para tanto, sugeria-se que as camadas médias 'esclarecidas' deveriam aproximar-se o máximo possível das camadas populares no sentido de conscientizá-las. Várias dessas ações resultaram de iniciativas de partidos políticos - muitos dos quais ainda estavam na clandestinidade. A retomada do feminismo no Brasil sob a proteção da ONU foi, então, pensada como uma possibilidade de realizar essa 'conscientização' das camadas populares. Ou seja, o movimento feminista tornou-se o passaporte para essa atuação.

Rose Marie Muraro diz que foi Mariska de Oliveira quem conseguiu, junto à ONU, o patrocínio "para a primeira reunião feminista do Brasil”, realizada no Rio de Janeiro. Para esse evento, "convidaram até o Celso Furtado para falar, além de muitos outros homens e mulheres". O auditório ficou superlotado. ${ }^{11}$ Muraro acrescenta que não sabe quem convidou Celso Furtado para falar. Diz, em forma de queixa, que não sabe por não ter sido ela quem organizou o evento. Reclama que as feministas nem a avisaram dessa reunião, "porque achavam que eu era uma estrela e que no feminismo não podia haver estrelas". Reclama, ainda, que quando formaram o CMB - Centro da Mulher Brasileira, ela foi até lá, mas estava na platéia (Muraro, 1999, p.176):

quando elas convidaram as pessoas depois da reunião para fundar o Centro da Mulher Brasileira, apareceram setenta mulheres do país inteiro, e eu fiquei lá, entre as outras, com Carmem da Silva e Heloneida, as três, tranqüilamente, como povo. Até hoje, nas organizações feministas eu não me meto, fico como povo. (Muraro, 1999, p.175)

Esta narrativa que Rose Marie Muraro faz do evento 'fundador' retrata a importância que ela tem nas identificações com o feminismo no Brasil. Ao estranhar sua própria ausência entre as organizadoras do evento, Muraro está dizendo que seu feminismo é anterior a essa data. Daí dizer que era considerada 'estrela', que por isso foi 'deixada' na platéia com Heloneida Studart e Carmem da Silva. Heloneida, como vimos, já havia participado do evento da ONU no México, e Carmem da Silva era conhecida por seu trabalho na re- 
vista Claudia. Esta, desde o início dos anos 60, tinha uma coluna nessa revista, na qual divulgava idéias feministas da Segunda Onda.

Rose Marie Muraro, apesar da queixa de ser apenas 'platéia' no evento fundador da ABI, chama para si a responsabilidade sobre a manutenção do $\mathrm{CMB}$, ao dizer que foi ela quem conseguiu recursos para que o Centro da $\mathrm{Mu}-$ lher Brasileira alugasse uma sala. Diz, então, que o dinheiro para ela ir ao México fora oferecido por Ecilda Ramos de Souza, diretora do Fundo Nacional de Desenvolvimento Educacional — FNDE. De acordo com Muraro, Ecilda "era feminista silenciosa", e localiza desta forma uma outra personagem, ligada ao feminismo. Esta, entretanto, não pertencia ao campo da esquerda. Informa, então, que não foi ao México, tendo pedido a Ecilda que entregasse o dinheiro para o CMB. Assim, com esse dinheiro, conseguiram alugar uma sala. Foi dessa forma, afirma, que conseguiu recursos para o CMB até os anos 90 (Muraro, 1999, p.176-7). Tais recursos permitiram não só manter a sede no centro da cidade do Rio de Janeiro, como, também, realizar projetos de in-

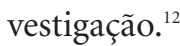

Dentro dessa mesma perspectiva, situando o ano de 1975 como fundador, Maria Amélia de Almeida Teles informa sobre a criação, em São Paulo, de um evento e um Centro semelhante ao do Rio de Janeiro:

Em São Paulo, realizou-se no mesmo ano, em outubro, o Encontro para o Diagnóstico da Mulher Paulista, patrocinado pelo Centro de Informação da ONU e pela Cúria Metropolitana. Desse encontro nasceu o Centro de Desenvolvimento da Mulher Brasileira. ${ }^{13}$

Interessante destacar que a reunião de São Paulo colocou-se em subalternidade em relação àquela ocorrida, em julho, no Rio de Janeiro. Enquanto o encontro do Rio foi chamado de "O papel e o comportamento da mulher na realidade brasileira", ou seja, considerava-se estar fazendo um evento de âmbito nacional, o evento realizado em São Paulo restringiu o título para aquele estado da Federação. Como já vimos, Maria do Espírito Santo, em seu depoimento, coloca o evento de São Paulo como uma "perna do Rio de Janeiro". ${ }^{14}$

Por sua vez, Maria Lygia Quartim de Moraes conta sobre os cuidados que foram tomados para a realização do Encontro para o Diagnóstico da Mulher Paulista, na Câmara Municipal de São Paulo, em outubro de 1975, com a "anuência da Cúria Metropolitana”. Lembra, ainda, os inúmeros cuidados que foram tomados para "não assustar a Igreja" com temas inaceitáveis para esta, como contracepção, sexualidade e aborto. ${ }^{15}$ Ainda de acordo com essa autora, 
as mulheres foram, naquele evento, identificadas como aquelas que estariam necessitando "romper os grilhões que ainda a prendem à superstição e à ignorância herdadas do passado”. Para tanto, seria necessário:

traçar, em conjunto com os representantes das sociedades amigos de bairros, sindicatos, entidades de pesquisa, associações em geral e pessoas interessadas, um programa específico para cada entidade, cujo objetivo principal será o de estimular a mulher a participar cada vez mais da vida associativa... (Moraes, 1990, p.15)

Em São Paulo, também surgiu, de forma semelhante à do Rio de Janeiro, o Centro de Desenvolvimento da Mulher Brasileira, em novembro de 1975 (Moraes, 1990, p.16). Foi ainda nesse ano, a 9 de outubro, que saiu o número ' 0 ' do jornal Brasil Mulher. Impresso em Londrina, no Paraná, com oito páginas, tendo à frente da editoria Joana Lopes (ibidem, p.15-6). Esse jornal teve vinte edições, com uma tiragem de 5 mil exemplares, tendo alguns números saído com dez mil. Sua periodicidade dependeu dos recursos que conseguia arrecadar com vendas e doações, os quais eram sempre escassos. ${ }^{16} \mathrm{O}$ número ' 1 ' desse jornal saiu em dezembro de 1975, trazendo um balanço do Ano Internacional da Mulher. O jornal iria usar, pela primeira vez, a palavra 'feminismo' no número '2', publicado no início de 1976. Essa palavra incomodava até mesmo algumas das mulheres que compunham a edição do jornal (Teles, 1993, p.88-9).

O próprio jornal vinculava-se muito mais à luta pela anistia e contra a ditadura do que às questões feministas. Muitas de suas editoras eram ligadas ao PCdoB. Maria Amélia de Almeida Teles relata, em seu livro A breve história do feminismo no Brasil, sobre isso:

O Brasil Mulher se propunha principalmente a defender a anistia a todos os presos e perseguidos políticos. E, com isso, ele rapidamente se afirma frente às forças políticas de oposição ao regime militar. Exemplares desse jornal chegavam a vários estados. Em diversos deles, como Bahia, Rio de Janeiro, Paraíba e Maranhão, além de São Paulo, as mulheres se organizavam para lê-lo, distribuílo e enviar notícias para a própria edição. (Teles, 1993, p.89)

Maria Amélia, em entrevista, narra o trabalho que fazia com os exemplares do jornal Brasil Mulher, assim como sua atuação e a forma como o jornal era feito. De acordo com ela, Joana Lopes, sua editora inicial, morava em 
Londrina; assim, por segurança, o jornal foi feito inicialmente naquela cidade do Paraná.

Ajudei — nossa! — e como, ajudei a fazer, ajudei a distribuir, a vender, ajudei nas discussões. No Brasil Mulher a gente fazia de tudo, eu fiquei de 75 a 79 no jornal, fiquei quatro anos ... nós tínhamos uma salinha que pagávamos, pagávamos a impressão, a distribuição, porque vender era mais ou menos assim: mesmo que vendesse tudo, não pagava de jeito nenhum. Então, éramos nós que fazíamos tudo, e assim, por exemplo, vinha o Brasil Mulher e um tanto ficava na minha casa. E eu já distribuía para pessoas que freqüentavam a minha casa. A casa da gente era uma sucursal, um 'aparelho'.

O Brasil Mulher eu distribuía e o discutia com 18 clubes de mães. Eu era amiga do padre. O padre deixava que eu fosse lá, porque tinha muito controle. Ele dizia: "vai lá, Amelinha, discutir com as mulheres, elas gostam"."

Maria Amélia usava o jornal Brasil Mulher para fazer discussão com as mulheres. Lia, com elas, trechos do jornal, e em seguida discutia. De acordo com ela, se não fizesse desse modo as mulheres não o leriam. ${ }^{18}$

O jornal Brasil Mulher foi publicado em Londrina até o segundo número; a partir daí, passou a ser publicado em São Paulo, circulando até março de 1979. Em 1977, Joana Lopes, sua primeira editora, deixou o jornal (Teles, 1993, p.89). Rosalina de Santa Cruz Leite, uma das editoras do Brasil Mulher, informa que o jornal era constituído por mulheres militantes do Partido Comunista do Brasil — PCdoB, da Ação Popular Marxista Leninista - APML e do Movimento Revolucionário 8 de outubro — MR8 (Leite, 2003, p.235-6).

Como se pode observar, o jornal e o movimento feminista serviam de passaporte para a atuação nos meios populares. Maria Amélia, por exemplo, era militante, havia muito tempo, do PCdoB, e levava o jornal Brasil Mulher como equipamento didático para aquilo que considerava ser um processo de "conscientização da mulher".

O jornal Brasil Mulher estava, também, ligado às lutas pela anistia. Já no número '0', surgido em 30 de maio de 1975, publicou uma entrevista e foto de Terezinha Zerbini nas páginas centrais. ${ }^{19}$ Algumas mulheres que passaram mais tarde a identificar-se com o feminismo começaram sua militância através do Movimento Feminino pela Anistia. ${ }^{20}$ Esse movimento, embora tivesse entre suas integrantes algumas mulheres que se identificavam com o feminismo, tinha como presidente uma mulher que dizia enfaticamente não ser feminista. 
Maria Amélia de Almeida Teles afirma que já era feminista quando passou a participar do Movimento Feminino pela Anistia. Depois é que passou a fazer parte da Sociedade Brasil Mulher, que publicava o jornal já citado:

no ano de 75 começou o movimento pela anistia, e eu entrei, apesar de a Terezinha Zerbini ... ela é anti-feminista, ela nunca entendeu feminismo.

Imediatamente, entrei pela porta dos fundos, eu era feminista, eu achava que tinha que ser movimento feminista pela anistia ... porque tudo ali era difícil, eu via muitas vezes os policiais perseguindo o movimento feminino pela anistia ... porque toda semana eu estava na cadeia visitando os presos... ${ }^{21}$

Convém, aqui, destacar que Maria Amélia de Almeida Teles, além de ter sido presa duas vezes durante a ditadura militar, teve o marido e a irmã presos. Em vista disso, e a exemplo de várias outras pessoas que se envolveram com o Movimento Feminino pela Anistia, fazia constantes visitas à prisão. Foi nessas visitas que entrou em contato com o Movimento liderado por Terezinha Zerbini, o qual foi, ao mesmo tempo, sua porta de entrada para o movimento feminista.

\section{OUTRAS NARRATIVAS, 'OUTRAS ORIGENS'}

Essas narrativas que colocam 1975 como ano inaugural do feminismo no Brasil são, entretanto, contestadas por outras participantes. Rose Marie Muraro, como já vimos, é uma delas. Diz que já era feminista antes dessa data, e que já atuava como tal. Convém destacar que foi por seu intermédio que o livro A mística feminina, ${ }^{22}$ da norte-americana Betty Friedan, publicado nos Estados Unidos em 1963, ganhou edição brasileira em 1971 (Muraro, cit., p.168).

Assim, Rose Marie Muraro não é a única que se refere à sua identificação com o feminismo como anterior ao 'marco fundador' de 1975, na ABI. A historiografia que narra esse acontecimento informa não ter sido a primeira vez que grupos de mulheres reuniam-se para pensar e discutir a "situação da mulher". Em 1972, a advogada Romy Medeiros realizou um congresso, promovido pelo Conselho Nacional da Mulher e liderado por ela. Romy Medeiros tinha uma história no movimento feminista. Em 1949 havia criado o Conselho Nacional de Mulheres, que lutava por direitos. Lutou, por exemplo, pelo Estatuto da Mulher Casada, que foi aprovado em 1962. Esse estatuto repre- 
sentou o fim do "marido como chefe da família". A partir de então, marido e mulher precisariam de consentimento mútuo para gerir os bens e para as decisões familiares (Pinto, cit., p.46-7).

Romy era bem relacionada com as elites do governo - portanto, não pertencia ao campo da esquerda, que lutava contra a ditadura. Mesmo assim, enfrentou dificuldades para realizar o congresso de 1972 — foi chamada várias vezes ao Dops, por causa disso. Desse evento haviam participado Rose Marie Muraro, Heleieth Saffioti e Carmem da Silva (ibidem, p.48-9). Entretanto, o evento não tem sido considerado um marco do feminismo da Segunda Onda no Brasil, diferentemente do evento de 1975, na ABI, certamente pelo fato de não ter sido promovido pelos grupos de esquerda.

Além desse evento promovido por Romy Medeiros, desde o início dos anos 70 começam a surgir, em cidades como Rio de Janeiro e São Paulo, grupos de reflexão. Esses grupos eram formados por mulheres que já se conheciam há mais tempo, eram amigas ou possuíam alguma afinidade. Eram grupos que se reuniam nas casas umas das outras (ibidem, p.49).

Albertina de Oliveira Costa, comentando a formação do feminismo no Brasil, identifica duas vertentes: uma vinda da França, e outra dos Estados Unidos. De acordo com ela, a vertente que vinha dos Estados Unidos tinha uma prática de 'grupos de reflexão', mais voltada para a transformação pessoal e cultural. E não se tratava de esquerda ou de direita. Ela lembra que a própria Betty Friedan (op. cit.) era uma militante trotskista, originalmente de formação marxista. ${ }^{23}$ Céli Pinto diz que um dos primeiros grupos de reflexão foi criado em São Paulo e começou a atuar em 1972, tendo uma longa duração (até 1975). Era formado por mulheres de camadas médias, intelectuais de esquerda. Duas dessas mulheres teriam vindo dos Estados Unidos; cita Walnice Nogueira Galvão (Pinto, cit., p.50) e, embora não a nomeie, a outra mulher é, certamente, Maria Odila Leite da Silva Dias, que, segundo ela, esteve nos Estados Unidos entre 1968 e 1971.

Na memória de Maria Odila Leite da Silva Dias, essa data de início do grupo retrocede a 1971. Foi nesse ano que passou a integrar, em São Paulo, um "grupo de conscientização feminista". Reuniam-se cada semana na casa de uma pessoa, e faziam leituras feministas. Relaciona as pessoas que dele faziam parte, na época:

Beti, a Valnice Nogueira Galvão, que é de teoria literária, ah, tinha uma moça que fazia exposições, esqueci o nome dela, eu sei que no grupo um dia apareceu 
a Marta Suplicy ... E durou muito esse grupo ... em 75 ainda existia, eu é que fui embora. ${ }^{24}$

Maria Odila diz que ainda participaram do grupo algumas pessoas como Albertina Costa e Branca Moreira Alves, que vinha, de vez em quando, do Rio. Nesses grupos, liam vários textos feministas.

Referindo-se ao grupo de reflexão de São Paulo, Maria Odila narra como foi sua identificação com o feminismo nos Estados Unidos. De acordo com ela, quando se divorciou, em 1968, foi para a Universidade Yale. Lá, embora estivesse preparando uma tese de doutorado sobre outro assunto, passou a se interessar pelo feminismo. Começou a comprar livros, a descobrir editoras. Quando voltou, passou a integrar o grupo de reflexão. Esse grupo era formado, também, por algumas pessoas já haviam morado nos Estados Unidos. A maioria falava inglês e francês: "Era um grupo muito internacionalizado ... muita literatura francesa nessa época e muita americana, todo mundo trazia livros, todo mundo que viajava trazia livros, quando eu voltei vim com uma biblioteca de estudos...”.

O que essas mulheres estavam trazendo do exterior era resultado do movimento feminista, que estava ganhando espaço nas ruas e na mídia em geral. No Brasil, entretanto, tudo isto era novidade.

No Rio de Janeiro, a partir de 1972 também apareceram grupos de reflexão. O primeiro grupo foi formado por Branca Moreira Alves, e durou até 1973 (Pinto, cit., p.50-1). Esse grupo também sofreu influência do feminismo dos Estados Unidos. Branca Moreira Alves estudava em Berkeley quando entrou em contato com o feminismo, participando, por três meses, de um desses grupos de reflexão. Ao chegar no Brasil, resolveu usar a mesma metodologia, reunindo mulheres. Fez, inicialmente, um só grupo com mulheres das mais diferentes idades. Entretanto, a diferença de geração estava inibindo as pessoas. Ela, então, dividiu o grupo entre as da geração de sua mãe - acima de 45 anos - e as de sua própria geração. Esse grupo das mais jovens durou de 1972 até o final de $1973 .{ }^{26}$

Outras mulheres também narram sua participação em grupos de reflexão. É o caso de Santinha - Maria do Espírito Santo - , que participou de um desses grupos no Rio de Janeiro:

nos grupos de reflexão você se mostrava: "eu sou Santinha, eu sou Jaqueline, eu sou fulana..." E a gente ia sentindo quais eram as dificuldades das outras, quais eram as preocupações; o que é que você queria resolver nesse mundo, qual era a 
sua busca, qual era o seu sonho. Entende? Em termos de "você mulher". O que é que você queria para melhorar a sua situação no mundo. Foi muito interessante esse período, e lindo ... Porque eu falava para você e aí você já trazia uma colega. Aí, no outro sábado, vinham mais quatro mulheres. Ávidas para falar, para ouvir. ${ }^{27}$

Suely Gomes Costa, em seu depoimento, narrou que foi convidada por Santinha para integrar o grupo de reflexão, mas sua reação inicial foi de desconforto:

Ela me chamou para várias reuniões ... eu não me via muito no campo dela. Eu era muito mais ligada às lutas da esquerda do que a qualquer outra coisa. Assim, ligada a problemas existenciais e tal, eu não era. Ela me chamou para uma reunião - eu fui. E aí, achei aquela reunião [e era] um "chororó" danado. As mulheres falando de dominação, dos maridos que tomavam conta e não sei quê... E eu me achava assim: a mulher que não tinha prisões, a mulher solta no espaço. Eu pensei: o que é que eu estou fazendo aqui, eu não vivo nenhum drama desses. E eu pensava isso. ${ }^{28}$

Nesse depoimento, convém destacar a forma como Suely pensava esses grupos de reflexão. Suas palavras refletem aquilo que grande parte da esquerda brasileira pensava desses grupos. E ela justifica essa avaliação ao lembrar que, naquele momento, ela estava "mais ligada às lutas da esquerda". Ela explica, ainda, como eram organizados esses grupos, e atribui tal formato ao feminismo norte-americano:

é do movimento feminista americano, isto de fazer sucessivos encontros com pequenos grupos de mulheres, de fazer uma metodologia de tomada de consciência. Não se pretendia homogeneizar as mulheres, mas era uma forma de estas entrarem em contato com ... as linhas da vida. Então eram sucessivas oficinas. ${ }^{29}$

Os grupos de reflexão não tinham nenhuma forma de regulamento. As reuniões tinham temas, mas não tinham pauta, discutia-se tudo. Albertina, citada por Céli Pinto, diz que "havia o lado terapia sem guru, nem terapeuta, de terapia autogestionada para mulheres que, no espaço competente, eram analisadas por especialistas". ${ }^{30}$

Em seu trabalho, juntamente com Jaqueline Pitanguy, Branca Moreira Alves descreve os objetivos e a metodologia do "Grupo de reflexão": 
grupos pequenos e informais, constituídos unicamente por mulheres. Essa tática desenvolveu-se espontaneamente. Surgiu pela necessidade de se romper o isolamento em que vive a maior parte das mulheres nas sociedades ocidentais, nuclearizadas em suas tarefas domésticas, em suas experiências individuais vividas solitariamente. A mulher constituiu assim um espaço próprio para expressar-se sem a interferência masculina, para compreender-se através de sua voz e da voz de suas companheiras, para descobrir sua identidade e conhecer-se. Nestes grupos a mulher descobre que sua experiência, suas dificuldades, frustrações e alegrias não são isoladas nem fruto de problemas unicamente individuais, mas, ao contrário, são partilhadas por outras mulheres. A descoberta dessa experiência comum, a transformação do individual em coletivo, forma a base do movimento feminista ... Se o que era aparentemente individual e isolado se revela, na verdade, como uma experiência coletiva, concretiza-se a possibilidade de luta e de transformação. ${ }^{31}$

Maria Luiza Heilborn também narra a formação, no Rio de Janeiro, de um grupo de reflexão. Esse grupo teria a vantagem de receber através de uma delas, a Marhel - Maria Helena Darcy de Oliveira — , toda uma literatura feminista que vinha da Europa, enviada por uma cunhada sua, então exilada na Suíça. Foi nessa ocasião que leram textos de Gisèle Halimi, Simone de Beauvoir, Ti-Grace Atkins e Scheila Rowbothan, entre outras. ${ }^{32}$ Ainda de acordo com Maria Luiza Heilborn, foi Mariska, a cunhada de Marhel, quem conseguiu o patrocínio da ONU para realizar o encontro que ocorreu, em 1975, na sede da ABI. Ela também faz sua narrativa 'fundadora' do evento, e o localiza nos grupos de reflexão. Assim, de acordo com ela, procuraram entrar em contato com o grupo de Branca Moreira Alves, e organizaram um evento que tinha o pomposo nome de "Pesquisas sobre o papel e o comportamento da mulher brasileira”. Não queriam usar o termo 'feminismo' para não assustar as pessoas, e, além disso, incluíram vários homens na programação. Várias pessoas ficaram com medo de participar, em virtude da repressão. E, foi assim que, entre 30 de junho e 6 de julho de 1975, no auditório da ABI, ocorreu o evento que reuniu alguns homens e muitas mulheres, e a participação destas as tornaria 'feministas históricas' - constituindo uma diferença em relação às demais. ${ }^{33}$

Surgido desse evento, o CMB - Centro da Mulher Brasileira - passaria a ter um perfil que, de acordo com inúmeros depoimentos, tornou-se, cada vez mais, marcadamente marxista. Anette Goldberg fala da existência de três principais tendências dentro do $\mathrm{CMB}$ - o feminismo liberal, o radical e 
o marxista ortodoxo. ${ }^{34}$ De acordo com ela, as ações iniciais do CMB foram mais de caráter liberal (Goldberg, 1987, p.108); entretanto, a partir de 1977 tornou-se mais e mais marxista (p.121). Entretanto, os depoimentos, desde o início, dão mais destaque ao perfil marxista: Maria do Espírito Santo diz que as mulheres do CMB do Rio de Janeiro eram, hegemonicamente, do PCB Partido Comunista Brasileiro. Nas palavras dela, "quase todas do Partidão". 35

Maria do Espírito Santo conta que participou do CMB, com outras colegas, por ser do Partido Comunista. De acordo com ela, "O Partido Comunista teve um papel fundamental na criação do movimento". Nesse caso, o partido é que teria aberto espaço, mostrando:

“Te organiza, mulher, tem espaço para vocês se organizarem.” E aí, quando eu fui, quando eu comecei o Centro da Mulher Brasileira — eu coloco isso até hoje —, fui com a cabeça de 'partidão': "eu vou para ganhar a cabeça das pessoas para entrarem no Partido Comunista”. Aí, o que se estava discutindo nos grupos ganhou minha cabeça ... discutindo as linhas, o cotidiano. Esse cotidiano que era meu, cheio de dificuldades... Isso foi me ganhando. E a tarefa que me levou para lá, eu coloquei em uma reunião do 'partidão': “essa tarefa eu não quero mais" ... Trazer mulheres para o Partido Comunista. Essa tarefa eu não quero. ${ }^{36}$

No depoimento de Maria do Espírito Santo explicita-se a tentativa de aparelhamento do movimento feminista pelo PCB, no Rio de Janeiro. Ela mesma é quem confessa ter entrado no movimento para trazer mulheres para o partido. Moema Toscano, falando das manifestações feitas pelas mulheres do $\mathrm{CMB}$, também esclarece: "o Partido Comunista arranjava um carro de som, então fazia uma passeata, chegava aqui na Cinelândia com discursos das feministas..." ${ }^{37}$

Convém destacar que, após a instalação da ditadura militar no Brasil, entre os vários grupos de esquerda que estavam sendo perseguidos, o PCB foi considerado pelos demais como 'conservador', por não ter participado diretamente da luta armada. Vários de seus ex-integrantes passaram a incorporar novos grupos envolvidos na luta armada. Maria Lygia Quartim de Morais diz que o PCB tinha sido "relativamente poupado do terror repressor, justamente por sua oposição à luta armada. Não desprezava, como equivocadamente o fez a nova esquerda por um determinado período, as oportunidades legais de trabalho político" (Moraes, cit., p.14).

Evidentemente, na disputa política no interior da esquerda, e dentro do movimento feminista, para aquelas que discordavam da atuação do PCB, este 
era acusado de ser de 'direita'. Convém lembrar que, enquanto no Rio de Janeiro os feminismos do CMB eram influenciados pelo PCB, em São Paulo a interferência maior era do PCdoB.

Ao identificar as tendências presentes dentro do CMB do Rio de Janeiro, Anette Goldberg afirma que Branca Moreira Alves representava a tendência liberal, enquanto Maria Luiza Heilborn representava a radical (Goldberg, 1987, p.119-20). Na entrevista de Branca Moreira Alves explicita-se o estranhamento desta em relação às ações que passaram a ser implementadas pelo CMB, principalmente a partir de 1977, quando a hegemonia passou a ficar nas mãos das militantes engajadas no PCB. Ela criticava a "militância de burguesia nas favelas". Argumentava que nem sabiam "como falar com as pessoas, tínhamos de ler Paulo Freire antes de ir". Diz, ainda, que os grupos de reflexão começaram a ser malvistos. Era considerado como "burguês, intimista; dizia-se que a sexualidade não era relevante, que se tinha que tratar de mulher e trabalho". Acusa, também, a esquerda de "utilizar movimento de mulheres como veículo, fazendo manipulação e só se concentrando no problema das classes". ${ }^{38}$ Esse depoimento de Branca atesta a forma como o feminismo — ou, pelo menos, uma vertente dele, representada pelos grupos de reflexão - estava sendo suplantado pelo ‘aparelhamento' que os partidos, na época clandestinos, estavam fazendo do movimento.

Anette Goldberg considera que o CMB acabou por perder a especificidade do pensamento feminista. Este foi "engolido pela idéia de um movimento social (ou popular) de mulheres cujas lutas gerais eram contra a ditadura, pela anistia e o restabelecimento das liberdades democráticas”. As lutas específicas que apareciam eram reivindicação de creches, "controle da natalidade, legislação protetora do trabalho feminino” (Goldberg, 1987, p.121). Reclama, ainda, que, naqueles 14 anos de ditadura militar, "a política das oposições tinha adquirido aspectos tão autoritários e repressivos quanto os do regime, e elas funcionavam como verdadeiras 'patrulhas ideológicas' com relação a tudo que se desviasse das ortodoxias” (ibidem, p.132-3).

A patrulha ideológica que se fazia consistia, por exemplo, em criticar o movimento feminista que se desenvolvia nos Estados Unidos, criticar a tradução de livros feministas que focalizassem temas como sexualidade, contracepção e aborto. Esse era o caso do livro de Kate Millett, que, ao ser traduzido no Brasil, foi alvo de severas críticas (ibidem, p.133-9). Além disso, criticava-se o feminismo norte-americano e seus atos. Um dos Boletins da CMB, de março de 1978, trouxe o seguinte 'comentário' a respeito de uma grande manifestação feminista ocorrida nos Estados Unidos: "São típicas da 
sociedade norte-americana as reivindicações específicas, que, por isto mesmo, morrem no seu próprio âmbito, sem envolver quase nunca uma discussão de caráter político mais profundo" ${ }^{39} \mathrm{E}$, afinal, o que seria mais profundo? Partidos e sindicatos.

Para esta perspectiva - que chamaríamos, como Anette, de 'Marxista ortodoxa' - os grupos de reflexão, as lutas pelo controle e autonomia do corpo, pela sexualidade, as manifestações pela liberação da mulher eram consideradas 'idéias específicas' e, portanto, divisionistas da luta geral, que consideravam prioritária: pela democratização, pela anistia, pelo socialismo. Para as pessoas envolvidas com o PCB ou outros partidos de esquerda, o que os grupos de reflexão fazia era, no mínimo, inútil. Elas se consideravam 'grupos mais atuantes'. Moema Toscano, ligada ao PCB, dá sua avaliação desses grupos de reflexão: "O grupo de reflexão era muito centrado nesse aspecto psicológico de catarse, grupos de auto-análise a partir da experiência particular: os casamentos que iam mal, novos casamentos. Era muito centrado nisso". ${ }^{40}$

Maria Lygia Quartim de Morais, escrevendo em 1990 sobre o feminismo dos anos 70, reconhece o preconceito que sentia em relação aos 'grupos de reflexão'. Estes eram acusados de parecerem uma espécie de “chá das cinco das ricas ociosas". Reconhece, então, que atuando nos movimentos de mulheres, ela e suas companheiras também faziam uma espécie de 'grupo de reflexão' através das

longas conversas após o expediente regular, quando falávamos de nossa vida pessoal, de nossas frustrações e medos, e que não passavam de formas espontâneas de reflexão. Mas por usarmos as 'outras' como álibi, isto é, falarmos do aborto delas, dos anticoncepcionais delas (as operárias, as mulheres da periferia etc.), terminávamos por esquecer que vivíamos os mesmos problemas e que poderíamos ser personagens de matéria sobre os nossos abortos, anticoncepcionais etc. Não eram só as outras que tinham problemas sexuais, que aturavam maridos prepotentes e relações deserotizadas, que dependiam financeiramente dos pais e maridos etc. (Moraes, cit., p.29)

Por ocasião das eleições de 1978, grande parte das mulheres do CMB deixaram de freqüentar as reuniões para participar da campanha eleitoral, e, embora tendo lançado um manifesto sobre as reivindicações das mulheres, não foi o voto feminista que prevaleceu (Goldberg, 1987, p.136-7). O fato de várias delas terem saído para 'cuidar das eleições' permitiu que houvesse novos espaços de discussão no CMB. Várias mulheres que estavam retornando do 
exterior, e outras que tinham deixado de ir ao CMB, passaram a reunir-se em suas dependências. Além disso, havia novas intelectuais, vindas da Europa e dos Estados Unidos, que estavam "trazendo suas experiências de participação em movimentos de liberação em seus respectivos países” (ibidem, p.137).

Assim, o afastamento de várias delas, para lutar por eleições, abriu espaço, no CMB, para a presença daquelas consideradas "pequeno-burguesas, divisionistas e envolvidas com grupos de reflexão". Estas passaram a se reunir no espaço do CMB. Adotaram como leitura para discussão o livro de Elena Belotti, ${ }^{41}$ e propuseram ao CMB uma jornada sobre "saúde e reprodução". Entretanto, após as eleições as demais retornaram e recomeçaram a organizar o I Encontro Nacional de Mulheres para o ano seguinte, entre 8 e 10 de março de 1979. Foi justamente na organização desse evento que as divergências se explicitaram. A proposta da jornada de 'Mulher e Reprodução' era rejeitada por ser este um "tema tabu” (Goldberg, 1987, p.138).

O grupo que permanecera reunido, enquanto as demais participavam da campanha eleitoral, não conseguia espaço nas discussões. Passaram assim a considerar que o CMB não era feminista. Seria apenas

um compartimento político das lutas pela transformação da sociedade brasileira, cuja especificidade provinha da composição feminina, muito mais do que da preocupação de travar lutas contra a discriminação e a opressão da mulher enquanto sexo em todas as instâncias: do pessoal ao social, do privado ao político. ${ }^{42}$

Resolveram, então, reunir-se fora do CMB. Redigiram um texto, que foi assinado por 21 mulheres. Entre estas, as "sócias fundadoras do CMB e algumas mulheres que buscavam uma aproximação com o feminismo nesta cidade, algumas recém-chegadas do exterior e tendo desenvolvido uma prática com os grupos feministas europeus e norte-americanos" (citado em Goldberg, 1987, p.139). Várias delas consideravam-se "feministas históricas" por terem participado do movimento no exterior, por terem criado grupos de reflexão, e por terem participado do evento fundador, de 1975, na ABI, e, ainda por serem as que haviam iniciado a organização do CMB.

Aquelas que haviam assinado o documento, chamado "Documento das 21", exigiam mudança na organização da CMB, queriam que tivesse uma estrutura horizontal, "na qual os mais diversos grupos se vinculariam através de uma coordenação de caráter rotativo, composta por participantes de cada grupo e por ele escolhidas, segundo seus próprios critérios” (ibidem). 
De início, parecia que a proposta seria aceita; entretanto, na terceira assembléia, quando a proposta seria posta em votação,

encontrou uma resistência totalmente inesperada expressa por intervenções de mulheres que não tinham participado das discussões anteriores e que, finalmente, perfizeram a maioria dos votos. Graças a esse procedimento 'golpista', o Centro saiu dessa assembléia com sua estrutura incólume e sua ideologia preservada. (Ibidem, p.140)

O grupo de reflexão independente, que existia antes de 1975, continuou reunindo-se fora do CMB. Adotaram o nome 'Grupo Ceres', devido a uma pesquisa que fizeram - sobre a identidade social e sexual da mulher — entre 1978 e 1979, com financiamento da Fundação Carlos Chagas. De acordo com Anette Goldberg, elas tinham orientação principalmente feministaliberal. Esse grupo era composto por Branca Moreira Alves, Comba Marques Porto, Jacqueline Pitanguy, Leila Linhares Barsted, Mariska Ribeiro e Sandra Boschi (ibidem).

Por outro lado, as assinantes do "Documento 21", juntamente com um grupo que discutia a violência contra a mulher, fundaram, em abril de 1979, no Rio de Janeiro, o Coletivo de Mulheres (ibidem). Esse coletivo explicitou, em junho de 1980, através de um documento, sua compreensão do que seria 'feminismo':

O feminismo, para nós, tem assim muitos jeitos: uma brincadeira, um sonho, uma política. Às vezes ele é sério, quase grave. Saímos aos auditórios, às ruas, para falar, reclamar, exigir, denunciar, agitar. Queremos o aborto livre e gratuito. Precisamos da democracia pelo direito básico da Existência. Falamos muito de sexualidade, e por que não? Detestamos os patrões e assim por diante... ${ }^{43}$

Essa definição de feminismo está em diálogo com as discussões no interior do $\mathrm{CMB}$, além de dizer que feminismo tem a ver com as chamadas 'especificidades' voltadas para os interesses das mulheres - como aborto, sexualidade —, mas elas ao mesmo tempo se colocam como engajadas na luta pela democracia, contra os patrões etc. Certamente esta era uma resposta ao grupo hegemônico do $\mathrm{CMB}$, que as acusava de "pequeno-burguesas e divisionistas".

Aproveitam para acusar as colegas do $\mathrm{CMB}$ de antidemocráticas, colocando-se como partidárias de organizações menos autoritárias. É assim que explicitam a maneira como entendem política: 
Muitas mulheres no Coletivo vêm ressabiadas da militância político-partidária, da reprodução da organização autoritária, da família, que assume tantas formas, e buscam outro tipo de participação coletiva e prezam, prioritariamente, a 'democracia horizontal' tentada no Coletivo... (Ibidem, p.5)

Mais adiante, falam da dicotomia "luta geral versus luta específica", de que tanto participaram, sendo acusadas, como já disse, de divisionistas e defensoras de lutas específicas e menos importantes:

Concebendo o feminismo como movimento libertário é que se questiona a antítese entre "luta geral e luta específica", e a própria classificação que rotula como no primeiro termo as lutas de classes e, no outro, reivindicações dos grupos estigmatizados - por exemplo, mulheres, negros, negras, homossexuaishomens e homossexuais-mulheres. Se se concebe o feminismo como um movimento social de cunho libertário busca-se a totalidade enquanto processo de transformação e o específico, no caso, só se justifica quando situado historicamente e relacionado a componentes deste processo. Assim, as formas de opressão na sociedade atual adquirem especificidades para cada categoria social, e é neste sentido que se percebe a pressão da mulher como específica, armando a participação das mulheres na luta contra o que mais diretamente lhe cabe de uma ordem discriminatória. (Ibidem, p.6)

Isto não significa que, no próprio interior do Coletivo de Mulheres, não surgissem diversos grupos e tendências. De acordo com Anette Goldberg, o Coletivo era formado por mulheres que se identificavam com o feminismo radical, o feminismo marxista ou socialista, e com uma cultura política alternativa (Goldberg, 1987, p.141).

Com relação ao CMB, Anette diz que, depois da 'ruptura', da 'abertura política' e do pluripartidarismo, surgiram várias vertentes políticas dentro do Centro. Isto especialmente após 1980. Assim, as marxistas ortodoxas, que tinham sido hegemônicas no Centro, sem se contagiar com outras tendências do feminismo, partiram para outras atuações, muitas vezes fora do Centro. Outras marxistas que permaneceram, junto com outras mulheres, puderam redefinir-se como feministas, adotando posições ligadas à questão da sexualidade (ibidem, p.141), por exemplo — tema anteriormente considerado tabu.

A ruptura que ocorreu no Rio de Janeiro também apareceu em São Paulo. Maria Lygia Quartim de Morais narra que, em junho de 1976, com a ajuda financeira de Ruth Escobar, surgia um novo jornal, chamado Nós Mulheres. 
Esse jornal passou a ser feito por cerca de vinte mulheres, distantes da "militância política organizada". Afirma ainda que esta, para muitas, era a "primeira experiência de intervenção social através da luta ideológica”. Pretendiam, através do jornal, privilegiar o tema 'mulher'. Proclamavam-se, já no primeiro número, como feministas (Moraes, cit., p.25). Para Rosalina de Santa Cruz Leite, o Nós Mulheres foi formado por pessoas recentemente vindas do exterior, ex-exiladas, muitas pertencentes ao Círculo de Mulheres de Paris, ${ }^{44}$ ligadas à vertente Debate, dissidência política que surge no exílio agrupando exmilitantes da Vanguarda Popular Revolucionária - VPR, da Vanguarda Armada Revolucionária Palmares — VAR-Palmares e do Partido Comunista Brasileiro - PCB, e também mulheres autônomas (Leite, cit., p.236).

Para Anette Goldberg, o feminismo que se forjou no Brasil não poderia ter, como o da França, "um inimigo principal” ${ }^{45}$ - que, no caso do feminismo internacional, era o patriarcado. A luta, aqui, tinha de se fazer, ao mesmo tempo, contra a opressão capitalista e contra a opressão patriarcal. O que se queria era formar uma sociedade socialista feminista. E, justamente para combater esses dois tipos de opressão, era preciso ter "dupla militância". ${ }^{46}$

A disputa entre as integrantes dos dois periódicos foi expressa de diversas formas. Maria Amélia, em sua entrevista, defende o Brasil Mulher da acusação de não ser "suficientemente feminista":

O Brasil Mulher é que me dá toda sustentação teórica para o feminismo poder falar o que quiser do Brasil Mulher, pois todo mundo fala que não é tão feminista, que o Nós Mulheres é mais. Tem aquela disputa, mas não me interessa, foi o que me ajudou. Porque lá a gente refletia sobre feminismo. ${ }^{47}$

Este foi um dos argumentos usados: o Nós mulheres foi considerado mais direcionado ao feminismo, ao passo que o Brasil Mulher estaria mais preso às lutas consideradas gerais. Por seu lado, o Nós Mulheres era acusado de "dividir a luta dos trabalhadores", de ser uma luta burguesa, porque somente a burguesia é que se interessava na "luta da mulher". Perguntavam, ainda: "de que maneira a mulher vai se libertar se é o capitalismo que oprime?”. E era preciso primeiro lutar pelo fim da ditadura, para depois buscar os direitos da mulher.

Evidentemente, essa disputa discursiva promoveu respostas de parte a parte. O jornal Brasil Mulher incorporou, progressivamente, temáticas específicas do feminismo, e, desse modo, o Nós Mulheres, em vários momentos, reforçou seu comprometimento com a luta pela democracia. O jornal Nós 
Mulheres circulou somente até 1978, tendo como jornalista responsável Marisa Correa.

Lutar no Brasil pela 'liberação das mulheres', no campo da esquerda e em plena ditadura militar, não permitia que o feminismo brasileiro fosse semelhante ao projeto que se desenvolvia na Europa e nos Estados Unidos, de onde vinham os livros, as idéias, as propostas. Certamente foi esse cenário o principal responsável pela data 'fundadora' de 1975. Aquelas que, anteriormente, estavam discutindo e formando uma nova feminilidade, não reconheceram como feministas as atuações de vários dos grupos que assim se denominavam, tornando a própria denominação 'feminista' alvo de intensas disputas. A luta contra a ditadura e a busca por 'conscientização' das camadas populares tornaram o movimento feminista e de mulheres uma maneira menos arriscada de realizar esse projeto.

Hoje sabemos que, das utopias e projetos revolucionários do século XX, o que lhes sobreviveu foi o projeto feminista. Certamente é por isso que podemos, hoje, questionar os marcos fundadores dessa revolução no Brasil. Afinal, uma nova correlação de forças está a exigir uma nova narrativa fundadora.

\section{NOTAS}

${ }^{1}$ Enquanto o feminismo de "Primeira Onda" esteve principalmente centrado na reivindicação de direitos políticos - como o de votar e ser eleita, o feminismo chamado de "Segunda Onda" surgiu depois da Segunda Guerra Mundial e deu prioridade às lutas pelo direito ao corpo, ao prazer, e contra o patriarcado. Nesse momento, uma das palavras de ordem era: "o privado é político".

${ }^{2}$ Entendo, como movimento feminista, as lutas que reconhecem as mulheres como especificamente e sistematicamente oprimidas. É a afirmação de que as relações entre homens e mulheres não são inscritas na natureza e, portanto, são passíveis de transformação. Como movimento de mulheres, entendo movimentos cujas reivindicações não são de direitos específicos das mulheres. Trata-se de movimentos sociais cujos componentes são, em sua maioria, mulheres. Ver, a esse respeito, HIRATA, Helena et al. Dictionnaire critique du féminisme. Paris: Presses Universitaires de France, 2000, p.125-30.

${ }^{3}$ Entendo que a narrativa atual das entrevistadas reflete, também, a "leitura" que fazem do passado, a partir das contingências do momento que estão vivendo. Ver, a esse respeito: FERREIRA, Marieta de Moraes; AMADO, Janaína. Usos \& abusos da História Oral. Rio de Janeiro: Fundação Getúlio Vargas, 1998.

${ }^{4}$ Trata-se de uma pesquisa financiada com bolsa de produtividade e de iniciação científica pelo $\mathrm{CNPq}$, intitulada: "Revolução do Gênero: apropriações e identificações com o feminismo (1964-1985)". Agradeço a participação e colaboração de Roselane Neckel, professo- 
ra que participa da pesquisa, e dos bolsistas: Joana Borges, Maise C. Zucco, Maria Cristina Athayde, Soraia de Mello, Veridiana Bertelli de Oliveira, Juliano M. Silveira e Gabriel Jacomel. Agradeço a leitura crítica de Cristina Scheibe Wolff e de Marcos Montysuma e a revisão da redação feita por Aimberê Araken Machado. Até o presente momento, foi possível fazer um extenso levantamento de livros, revistas e jornais que divulgaram o feminismo no período. Além disso, foi programada a realização de quarenta entrevistas orais com pessoas entre 50 e 69 anos (trinta mulheres e dez homens). Já realizamos 22 entrevistas com mulheres e quatro com homens que narram como, no período de 1964 a 1985, passaram a se identificar com o feminismo.

${ }^{5}$ Entrevista concedida por Heloneida Studart, realizada por Roselane Neckel, em 16.02.2005, no Rio de Janeiro transcrita por Juliano M. Silveira e Luciana Rosar Fornazari Klanovicz.

${ }^{6}$ Entrevista concedida por Moema Toscano, realizada por Roselane Neckel, em 16.02.2005, no Rio de Janeiro, transcrita por Maria Cristina Athayde.

${ }^{7}$ Entrevista concedida por Sônia Malheiros Miguel, realizada por Joana Maria Pedro, em Florianópolis, no dia 17.01.2005, transcrita por Soraia Caroline de Mello.

${ }^{8}$ Entrevista concedida por Maria do Espírito Santo Tavares dos Santos, realizada por Roselane Neckel em 14.02.2005, no Rio de Janeiro, e transcrita por Soraia Mello.

${ }^{9}$ Entendo "identificação" na perspectiva de Stuart Hall como um processo de "tornar-se", ou seja, uma construção, um processo nunca completado; dessa forma, a identificação é "condicional". Ver HALL, Stuart. Quem precisa da identidade? In: SILVA, Tomaz Tadeu da (Org.) Identidade e diferença: a perspectiva dos estudos culturais. Petrópolis: Vozes, 2000, p.106.

${ }^{10}$ PINTO, Céli Regina Jardim. Uma história do feminismo no Brasil. São Paulo: Fundação Perseu Abramo, 2003, p.58.

${ }^{11}$ MURARO, Rose Marie. Memórias de uma mulher impossível. Rio de Janeiro: Rosa dos Tempos, 1999, p.175.

${ }^{12}$ TABAK, Fanny. Mulheres públicas. participação política \& poder. Rio de Janeiro: Letra Capital, 2002, p.52.

${ }^{13}$ TELES, Maria Amélia de Almeida. Breve história do feminismo no Brasil. São Paulo: Brasiliense, 1993, p.86.

${ }^{14}$ Entrevista concedida por Maria do Espírito Santo Tavares dos Santos, cit.

${ }^{15}$ MORAES, Maria Lygia Quartim de. A experiência feminista dos anos 70. Araraquara: Unesp, 1990, p.14-5.

${ }^{16}$ LEITE, Rosalina de Santa Cruz. Brasil mulher e Nós mulheres: origens da imprensa feminista brasileira. Revista Estudos Feministas, Florianópolis, v.11, n.1, p.234-41, jan-jun. 2003, p.237.

${ }^{17}$ Entrevista concedida por Maria Amélia de Almeida Teles, realizada por Joana Maria Pe- 
dro no dia 24.08.2005, em São Paulo, transcrita por Soraia Melo, Veridiana Bertelli de Oliveira e Maria Cristina Athayde.

${ }^{18}$ Idem.

${ }^{19}$ Terezinha Zerbini foi uma grande liderança nacional do Movimento Feminino pela Anistia — MFA. Esse movimento surgiu em 30.05.1975.

${ }^{20}$ É o caso, por exemplo, de Lourdes Bandeira. Entrevista concedida por Lourdes Bandeira realizada em Florianópolis, no dia 28.11.2003, por Joana Maria Pedro, transcrita por Maria Cristina Athayde.

${ }^{21}$ Entrevista concedida por Maria Amélia de Almeida Teles, cit.

${ }^{22}$ FRIEDAN, Betty. A mística feminina. Petrópolis: Vozes, 1971.

${ }^{23}$ Entrevista concedida por Albertina de Oliveira Costa, realizada por Joana Maria Pedro no dia 02.08.2005, na Fundação Carlos Chagas (São Paulo), transcrita por Soraia Mello.

${ }^{24}$ Entrevista concedida por Maria Odila Leite da Silva Dias, realizada por Roselane Neckel em 24.06.2005, em São Paulo, transcrita por Veridiana Bertelli de Oliveira.

${ }^{25}$ Idem.

${ }^{26}$ GOLDBERG, Anette. Feminismo e autoritarismo: a metamorfose de uma utopia de liberação em ideologia liberalizante. Rio de Janeiro, 1987. 217p. Dissertação (Mestrado em Ciências Sociais) — Instituto de Filosofia e Ciências Sociais, Universidade Federal do Rio de Janeiro. p.101.

${ }^{27}$ Entrevista concedida por Maria do Espírito Santo Tavares dos Santos, cit.

${ }^{28}$ Entrevista concedida por Suely Gomes Costa, realizada por Joana Maria Pedro em Florianópolis, no dia 17.02.2004, transcrita por Maise Zucco.

${ }^{29}$ Idem.

${ }^{30}$ Costa, Albertina. É viável o feminismo nos trópicos? Resíduos de insatisfação — São Paulo, 1970. Cadernos de Pesquisa, n.66, ago. 1988. São Paulo: Fundação Carlos Chagas; citado em PINTO, C. R. J., op. cit., p.50.

${ }^{31}$ ALVES, Branca Moreira; PITANGUY, Jacqueline. O que é feminismo. São Paulo: Brasiliense, 1982, p.66-7.

${ }^{32}$ Entrevista concedida por Maria Luiza Heilborn, citada por GOLDBERG, A., op. cit., 1987, p.101.

${ }^{33}$ Entrevistas concedidas por Maria Luiza Heilborn e Branca Moreira Alves, citadas por GOLDBERG, A., op. cit., 1987, p.104.

${ }^{34}$ Entendo como "feminismo liberal" o movimento que luta pela promoção de valores individuais, pela igualdade entre homens e mulheres, e que reivindica leis que promovam essa igualdade completa. Como "feminismo radical", a luta contra o sistema patriarcal e as formas diretas e indiretas de poder falocrático. Muitas delas defendem a necessidade de um "separatismo radical", negando aos homens o direito de falar em nome das mulheres. 
Como "feminismo marxista", aquele que afirma que a verdadeira liberação das mulheres somente ocorrerá num contexto de transformação global. Ver HIRATA, Helena et al., op. cit.

${ }^{35}$ Entrevista concedida por Maria do Espírito Santo Tavares dos Santos, cit.

${ }^{36}$ Idem.

${ }^{37}$ Entrevista concedida por Moema Toscano, cit.

${ }^{38}$ Entrevista concedida por Branca Moreira Alves, citada por GOLDBERG, A., 1987, p.11920.

${ }^{39}$ Boletim do CMB III (5), de março de 1976, citado por GOLDBERG, A., 1987, p.119-20.

${ }^{40}$ Entrevista concedida por Moema Toscano, cit.

${ }^{41}$ Trata-se de BELOTTI, Elena Gianini. Educar para a submissão. Petrópolis: Vozes, 1987.

${ }^{42}$ Depoimento constante de Cadernos da Associação das Mulheres, n.3, ago. 1979, p.44-5, citado em GOLDBERG, A., op. cit., 1987, p.139.

${ }^{43}$ Reflexões sobre o feminismo. Coletivo de Mulheres do Rio de Janeiro, jul. 1980, p.2.

${ }^{44} \mathrm{O}$ Círculo de Mulheres de Paris funcionou entre 1975 e 1979. Era composto por mulheres brasileiras exiladas que constituíram uma organização feminista.

${ }^{45}$ A idéia de um inimigo principal como o sistema patriarcal foi definido no artigo de DELPHY, Christine. L’ennemi principal. Partisans. Libération des Femmes Année 0. Paris: F. Maspéro, 1974.

${ }^{46}$ GOLDBERG, Anette. Le dire et le faire feministes: une approche socioculturelle du Brésil Contemporain. Paris, 1991. 632p. Tese (Doutorado em História e Civilização) - Universidade de Paris VII. p.228-9.

${ }^{47}$ Entrevista concedida por Maria Amélia de Almeida Teles, cit. 